\title{
Design and Construction of Automatic Fish Feeder using Atmel 8052 Microcontroller
}

\author{
*OJO, KO; BENARD, OA
}

\author{
Department of Science Laboratory Technology, Faculty of Science, University of Benin, \\ Benin City, Nigeria.*E-mail: meetengrodu@gmail.com,talk2smithot@gmail.com \\ Tel: 08037999582
}

\begin{abstract}
This paper was proposed to design an automatic fish feeder system using Atmel microcontroller application. In a way, it is to control the fish feeding activity by using a fish feeder that combined the mechanical and electrical system to form a device which control the fish feeding activity. This device consists of feed storage, feed stand, display unit, microcontroller and DC motor. The feeds controlled by DC motor which is located under feed storage. A control system was then attached to this device allowing the fish to be fed at preset time as required by user. Hence, promising efficiency and productivity in fish pond in long run. Display unit his is basically the user interface where working of the system is displayed on a screen so that the user have an idea what is going on the system. The message will be displayed on a 16 by 2 liquid crystal display. The controller came with a keypad giving users more option in determining the suitable speed for the motor. In addition, the feed in the automatic fish feeder system will be controlled by the rotation speed of DC motor. Test results at the discharge interval of 4hours and dispensing time of 90minutes within 24hours showed that $15 \mathrm{~kg}$ of feeds were evenly broadcast across the pond of $12 \mathrm{~cm}$ less amount of feed lost was recorded compare to manual feeding. The machine adequately manages and preserves feed under harsh conditions.
\end{abstract}

\section{DOI: https://dx.doi.org/10.4314/jasem.v22i7.2}

Copyright: Copyright $\odot 2018$ Ojo and Benard. This is an open access article distributed under the Creative Commons Attribution License (CCL), which permits unrestricted use, distribution, and reproduction in any medium, provided the original work is properly cited.

Dates: Received: 08 April 2018; Revised: 30 May: 2018; Accepted: 04 June 2018

Keywords: Automatic, Microcontroller, Aquarist, Fish Pond, Fish Feed.

Nigeria as a country has been depend mainly on oil over a long period of time and this has resulted to a neglect of several other source of revenue generation away of these is the agricultural sector. Government has therefore seen the need to revamp agricultural sector as a way of adequately generating sufficient food consumption and food security instead of importing food. Fish farming is one of the most interesting fields in the agricultural sector as adequate production in Nigeria would give a great bust to the country gross domestic product (GDP). In 2016 it was reported that Nigeria remains the highest fish importer in African with estimated 950 metric tons of imported frozen fish valve over $\$ 700 \mathrm{~m}$ annually. Feeding fish is labor-intensive and also expensive. Feeding frequency is dependent on labor availability, farm size, as well as fish species and sizes. Large catfish farms with several ponds can usually be fed only once per day because of time and labor limitations, while this may be done twice per day at smaller farms. Generally, growth and feed conversion increases with feeding frequency. In the intensive fish culture systems, fish may be fed as many as five times a day in order to maximize growth at optimum temperatures (Yeoh et al, 2010). Food and feeding are the role important factor in the production, and then the management of the feeding is a main challenge in agriculture sector (Muhammad, 2013). This has prompted the design, microcontroller based automatic fish feeder that would curtail the challenge of overeating and under eating. This machine is design in such a way that it only dispenses feed at a preset time and also has the ability of repeating the task daily. It helps aquarist to feed their pet fish when he or she is on a vacation or too busy to maintain a regular feeding schedule (Siti, 2015). Especially in the case when one does more than one job or always have a busy schedule at place of work as the case maybe, the machine is helpful in this case because of its ability to regulate without any human intervention. Drudgery involved in manual feeding discourages aqua culturists, as it consumes time and human capital (Ozigbo et at, 2013). Not that it only boring feeding fishes manually but also lead to fed wastage and as such overeating is bound to happen.Aquaculture (fish cultivation), a rapidly-growing entrepreneurial activity, contributes to food security and poverty alleviation in many developing nations (Ogunlela and Adebayo, 2016).

In view of these problems, the objective is to design and construct automatic fish feeding system, ensure an accurate amount of fish feed to be dispensed at predetermined time and to embed a user control 
interface and warning system to the fish feeding system.

\section{MATERIALS AND METHOD}

The automatic fish feeder complete circuitry is been analyzed here with the different modules in focus.

Power supply: This is the circuit that supplies power to the full system. It obtains its power source from a 220 voltas ac power supply source, to deliver a 5 volts dc power output. The circuit diagram is shown in Fig 1 .

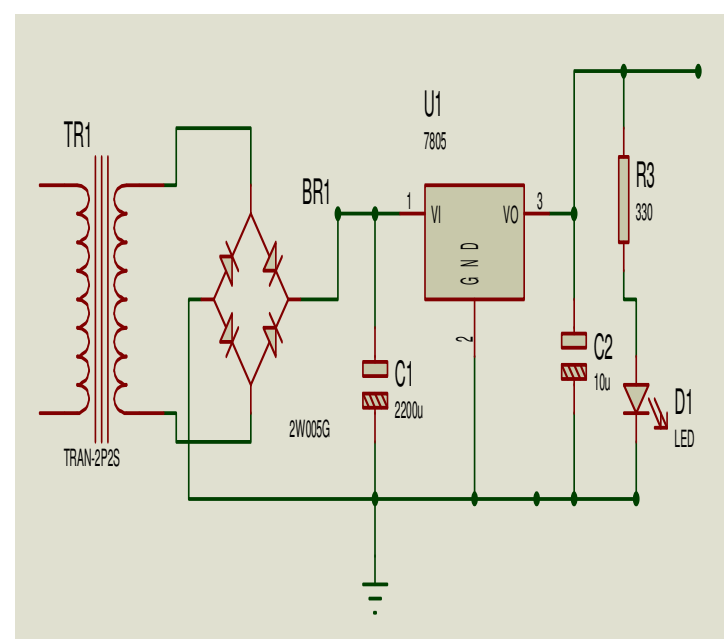

Fig. 1: The power supply unit

TRI: This is the step down transformer. A transformer voltage of $12 \mathrm{Vac}$ or above is required. The current should be enough to supply the requirement of the circuit. The transformer (T1) chosen is $12 \mathrm{Vac}$ at $300 \mathrm{~mA}$.

D1-D4: These are the rectifier circuit. The diodes chosen must have a peak inverse voltage (PIV) that must be able to withstand twice the peak voltage $\left(\mathrm{V}_{\mathrm{p}}\right)$ of the transformers output and a forward current $\left(D_{c}\right)$ of 1.5 times the output current of the transformer.

$\mathrm{V}_{\mathrm{p}}=\sqrt{ } 2 \mathrm{Vrms}$

Where $V_{p}$ is the peak voltage of the transformer output and $\mathrm{V}_{\mathrm{rms}}$ is the actual output voltage from the transformer $=12 \mathrm{Vac}$

$\mathrm{D}_{(\text {piv })}=2 \times \mathrm{Vp}$

Where $\mathrm{D}_{\text {(piv) }}$ is the PIV of the rectifier diode

$C_{l}$ : This is the filters capacitor. Electrolytic capacitors come with a capacitance and a voltage rating.

Voltage Rating: The voltage of the capacitor $\left(\mathrm{V}_{\mathrm{c}}\right)$ must be able to withstand $150 \%$ of the output voltage from the diode.

$\mathrm{V}_{\mathrm{C}}=150 \%$ of $\mathrm{V}_{\mathrm{DP}}$

Where $\mathrm{V}_{\mathrm{DP}}$ is the peak output voltage from the diodes

But $\mathrm{V}_{\mathrm{DP}}$ is given as

$\mathrm{V}_{\mathrm{DP}}=\mathrm{V}_{\mathrm{p}}-\mathrm{V}_{\mathrm{D}}$

Where $V_{p}$ is the peak voltage of the transformer and $\mathrm{V}_{\mathrm{D}}$ is the voltage drop of the diodes

Capacitance Rating: The capacitance of the capacitor must be such that it could reduce the ripple voltage $\left(\mathrm{V}_{\mathrm{R}}\right)$ to about $30 \%$ of the output peak voltage from the diodes.

$\mathrm{V}_{\mathrm{R}}=30 \%$ of $\mathrm{V}_{\mathrm{DP}}$

From the ripple voltage equation $\left(\mathrm{V}_{\mathrm{R}}\right)$, we could get the capacitance

$\mathrm{V}_{\mathrm{R}}=0.3 \mathrm{~V}_{\mathrm{DP}}$

Where $V_{R}$ is the ripple voltage; $I_{\max }$ is the maximum current from the diodes/ transformers $(300 \mathrm{~mA}) ; \mathrm{F}$ is the frequency of supply $(50 \mathrm{~Hz}) ; \mathrm{C}$ is the capacitance of the capacitor in Farads and U1 is the voltage regulator.

Regulator specifications are (i) Maximum input voltage $=30 \mathrm{~V}$ (ii) Maximum output voltage $=5.5 \mathrm{~V}$ and (iii) Operating temperature $=0 \%-150 \%$

For effective Voltage regulation, the minimum input voltage should be:

$\mathrm{V}_{\min }=\mathrm{V}_{\text {out }}+\mathrm{V}_{\text {re }}$

Where $\mathrm{V}_{\min }$ - Minimum input voltage; $\mathrm{V}_{\text {out }}$ - required output voltage: $5 \mathrm{~V}$; $\mathrm{V}$ ref - Datasheet Stipulated reference voltage; $3 \mathrm{~V}$ and the regulator chosen is: $\mathrm{U}_{1}$ $=7805$

$C_{2}$ is a transient capacitor. The rating is stipulated in the 7805 voltage regulator's data sheet as $0.1 \mathrm{uF}$. Hence, $\mathrm{C}_{2}=0.1 \mathrm{uF}$

This capacitor helps for smoothening of the output from the voltage regulator. It is also to prevent spikes in the DC output voltage waveform in the event of transient disturbances. It is known as a buffer capacitor whose value is gotten from the data sheet of the regulator. 
Current limiting resistor calculation:

$\mathrm{R}_{1}=(\mathrm{Vs}-\mathrm{Vd}) / \mathrm{Id}$

\section{RESULTS AND DISCUSSION}

The machine's hopper, shown in plate A and B below (approximately $2.5 \mathrm{~kg}$ ) capacity was filled to the brim and allowed to discharge till the tank was empty with time interval of four hours and dispensing time of 90minutes. Total amount of feed filled was delivered rightly. The feeding efficiency was found to have improved significantly when compared to manual feeding as stated above. The machine delivers both fingerlings and adult fish feed from powder form to about $8 \mathrm{~mm}$. The price of the machine is affordable and operation is simple, it can be operated by young and old. Its feeding time is flexible.

Microcontroller Unit: The microcontroller unit circuit is the heart of the project. This is where the program for the control part of the project is written and burned using assembly language and a universal programmer, respectively. The circuit diagram is as shown below

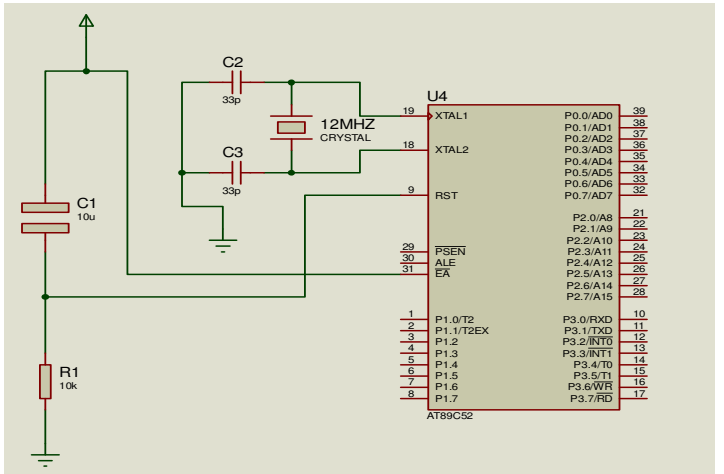

Fig 2: Microcontroller unit

The 8052 microcontroller hardware circuit is usually a very flexible one and all the surrounding components are given a recommended range of values, by the datasheet but the actual values can be chosen by the programmer, which we successfully did. The ranges of values given for the 8052 microcontroller hardware are as follows: Reset capacitor: $4.7 \mu \mathrm{F}$ to $10 \mu \mathrm{F}$; Reset resistor: $8.2 \mathrm{~K} \Omega$ to $15 \mathrm{~K} \Omega$; Crystal oscillator: $4 \mathrm{MHz}$ to $32 \mathrm{MHz}$; Crystal capacitors: $27 \mathrm{pF}$ to $47 \mathrm{pF}$

For the programming of the microcontroller for the automatic fish feeding system, the chosen values are as follows Reset capacitor $\left(\mathrm{C}_{1}\right): 10 \mu \mathrm{F}$; Reset resistor $\left(\mathrm{R}_{1}\right): 10 \mathrm{~K} \Omega$; Crystal oscillator $\left(\mathrm{X}_{1}\right): 12 \mathrm{MHz}$; Crystal capacitors $\left(\mathrm{C}_{2} \& \mathrm{C}_{3}\right): 33 \mathrm{pF}$.

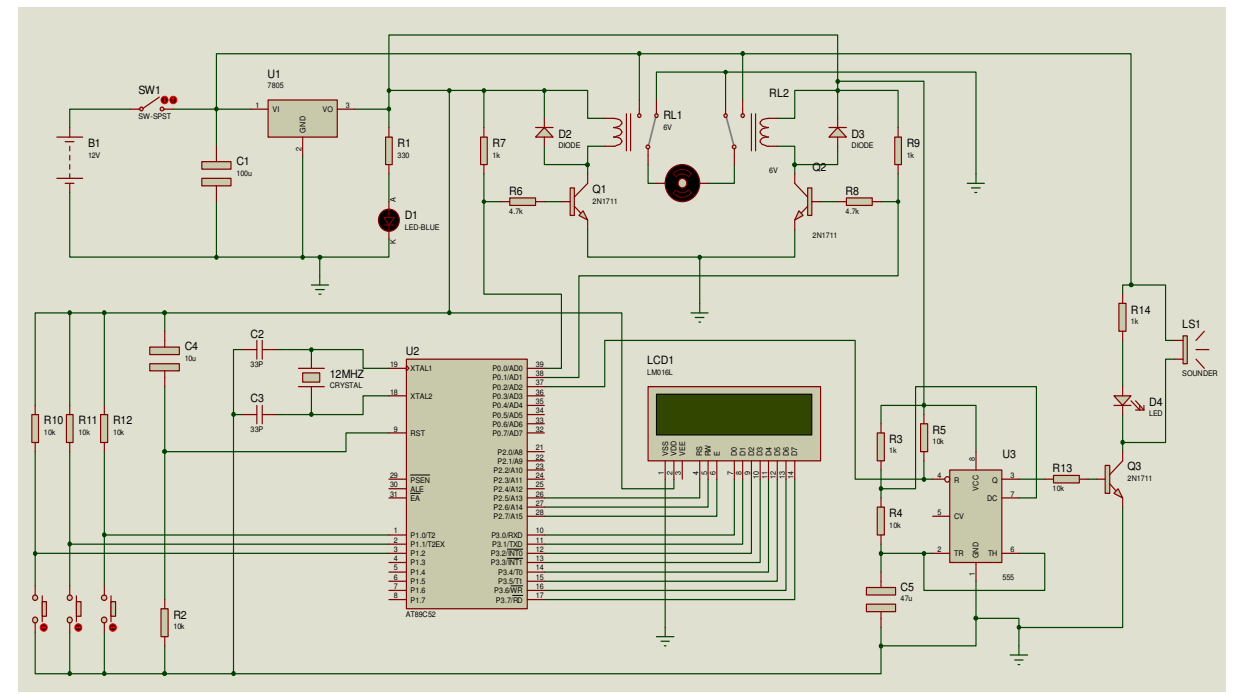

Fig 3: complete schematics diagram of an automatic fish feeder

Mode of Operation: The schematic diagram shown in figure 3 is the complete circuit diagram of automatic fish feeder based microcontroller system it work is such that a feeding dispersal mechanism controlled using an electric motor, will be controlled using a program written and burned into the ROM of a microcontroller. This motor will operate in such a way that when it moves forward, the feeding stops and when it moves backwards, the feeding continues. The system has input units which comprises of push buttons that will be used by personnel to set the duration of the feeding of the fishes as well as setting the quantity of feeds that will be introduced into the pond at stipulated times. There is also a screen which 
is made up of a 16 by 2 LCD screen which will be used by the user to observe the working of the system at all times and on which basic operations will be observed. The screen is driven by the microcontroller. The complete system operates on a 5 volts power supply unit which is obtained from a 12 volts dc battery. There is an alarm circuit that will be programmed to remind the user about the exhaustion of the feeds supply. This alerting unit is driven by a multivibrator which is built using a 555 timer connected in the astable mode.

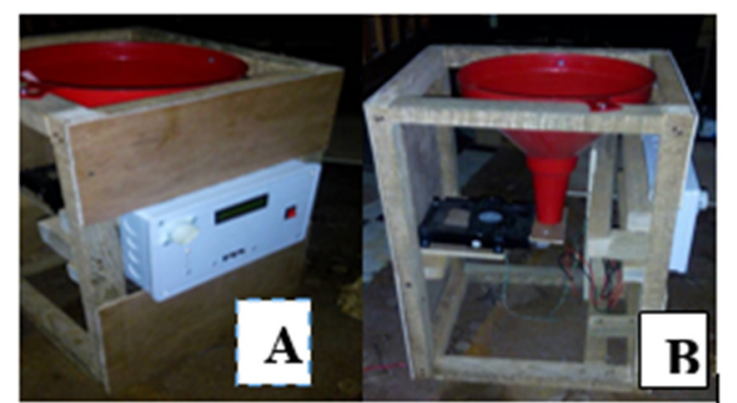

Plate 1: Plate A and B showing the front and side view respectively

Conclusion: A microcontroller based automatic fish feeder was designed and constructed. It main components are; DC motor, dispensing mechanism, hopper and power supply. The device was assembly into Circuitry and tested; during the testing analysis modularization and interface design were also tested. Each module in case of the software were tested to know whether it performs the functions assigned to it and also to know whether each of the module can interact as required by transferring and returning data in form of a signal. The essence of this is to check for the functionality of the system in question for optimal performance.

\section{REFERENCE}

Muhammad, HBMJ (2013). Modeling and control of the fish feeder system, Faculty of Mechanical and Manufacturing Engineering UniversitiTun Hussein Onn Malaysia.

Ogunlela, AO; Adebayo, AA (2016). Development and Performance Evaluation of an Automatic Fish Feeder. J. Aquaculture Res. Develop. 7:40

Ozigbo, E; Anyadike, C; Gbadebo, F; Okechukwu, R; Kolawole, P (2013). Development of an automatic fish feeder. Afr. J. Root. Tuber. Crops. $10(1): 32$

Siti, AS (2015). Design and fabrication of an automatic fish feeding system for home aquarium. Faculty of manufacturing engineering university of Malaysia Pahang.

Yeoh, SJ; Taip, FS; Endan, J; Talib, RA;Siti, MK(2010).Development of Automatic Feeding Machine for Aquaculture Industry. Pertanika J. Sci. Technol. 18 (1):105- 110. 